\title{
Cultivating a Gratitude Thinking Habit and Exploring Its Effects on Psychological Well-being: An Exploratory Longitudinal Study
}

Edmund Tak Tsun $\mathrm{LO}^{1}$ and Freedom LEUNG ${ }^{2}$

${ }^{1}$ Department of Psychology, the Chinese University of Hong Kong, Hong Kong;

edmundlo@link.cuhk.edu.hk, https://orcid.org/0000-0002-5926-2430

${ }^{2}$ Shaw College, the Chinese University of Hong Kong, Hong Kong;

yiukinleung@cuhk.edu.hk

Data available on osf.io upon request. No conflict of interest in this study was noted in relation to the authors' affiliation and funding. Ethics approval was given to the research proposal by the Department of Psychology of the Chinese University of Hong Kong with its adherence to relevant ethical guidelines. The authors are indebted to Shaw College, the Chinese University of Hong Kong that funded and supported the study. 


\begin{abstract}
This present study explored a novel approach of gratitude intervention by also focusing real-life habit formation as an intervention target. 180 Chinese college students were asked to do gratitude thinking before sleeping every night for 84 days while self-reporting daily their habit automaticity of and compliance in nightly gratitude. The effects of practices of gratitude thinking on improvements of life satisfaction, grateful affect and dispositional gratitude were mediated via the habit automaticity formed; for decrease of hostility, practices had a direct effect. Repetition and automaticity reciprocally predicted each other in different time points through 12-week follow-ups. Nonlinear regression fitted an asymptotic curve on each individual's automaticity over the 84 days of intervention. Parameters produced suggested 110 days were needed to reach an automaticity which could sustain gratitude thinking for 4 weeks without further intervention. Overall, results favored the consideration to include habit formation as part of future gratitude interventions.
\end{abstract}

Keywords: gratitude intervention, habit formation, mediation, modelling, automaticity 
Gratitude, originating from the Latin word "gratia", was seen as a virtue in many religions (Carman \& Streng, 1989). In contemporary research, when seen as a dispositional characteristic of a person or emotional reaction in response to events (Roberts, 2004), gratitude was suggested to be positively related to different constructs of psychological well-being (McCullough et al., 2002) beyond the influence of the Big Five facets of individual differences (Wood et al., 2009). Emmons and McCullough (2003)'s hallmark experimental study, which suggested improvement of psychological well-being was possible through regularly listing things that one was grateful with, marked the start of a series of research into gratitude interventions. These interventions were often in the forms of writing gratitude lists or letters for multiple times over days or weeks (e.g. Rash et al., 2011; Boehm et al., 2011). They aimed to evoke positive emotions, encourage grateful interpretation, and facilitate gratitude expression (Froh et al., 2009).Various experiments suggested associations between gratitude intervention and a number of benefits, including increased positive affects and decreased negative affects (Emmons \& McCullough, 2003), increased life satisfaction (Dossett, 2011), decreased negative thoughts about body (Geraghty et al., 2010), decreased anxiety symptoms (Kerr et al., 2015) and decreased depressive symptoms (Seligman et al., 2005).

A qualitative review (Wood et al., 2010) and a meta-analysis (Davis et al., 2016) called for cautious interpretation on efficacy of gratitude, which was varied across experimental 
studies and overall found to be only modest or small when compared with active control

groups. Modification on gratitude interventions was recommended in improving the efficacy.

In these reviews, gratitude interventions were seen as having possibly played a role in shaping the participants' habits of gratitude.

\section{Cultivating a habit of gratitude thinking as an improved form of gratitude intervention}

Habit has been studied since the behavioural era (e.g. Hull, 1943) given its predictive power on frequency of behaviours concerned. From the lens of learning and behaviours, habit was understood as an associative response triggered by context and cues after extended training (Dickinson et al., 1995), reflexive in nature, in contrast with goal-directed behaviours (Balleine \& O’Doherty, 2010). Habit was commonly measured by observing animal or human participants' (e.g. Hogarth \& Chase, 2011) responses upon manipulation of the contingency reward. Outside laboratory manipulation, paper-and-pencil measures of habit were commonly used in health psychology studies under real-life contexts. Among them, the Self-Report Habit Index (SRHI, Verplanken \& Orbell, 2003) was designed to capture automaticity of habit, assuming people can be aware of such through reflection. It was used in over a hundred studies (Gardner, 2015). SRHI did not only predict the frequency of the concerned behaviours (Verhoeven et al., 2012), but also contributed to related positive outcomes (Galla \& Duckworth, 2015). SRHI could also be applied to mental activities, for example contributing unique variance in the prediction of psychopathology (Verplanken et al., 
2007). From a theoretical perspective, automaticity provided extra predictive power as a process of the concerned behavioural or mental activities. Watkins and Nolen-Hoeksema (2014) further argued that automatic mental habits were "a central process within psychopathology" and that directly targeting the habit automaticity would improve the efficacy and durability for mental health interventions.

The current exploratory study was a response to the call of improving the efficacy of gratitude intervention by including automatic habit as part of the target of gratitude intervention. Specifically, the gratitude intervention would be arranged in a real-life context, namely before sleeping, versus an experimentally manipulated setup (e.g. forms provided by researchers for gratitude list), so that formation and maintenance of habit in real life were possible. It was expected that, the higher the habit automaticity, the higher frequency of gratitude thinking before sleeping at follow-ups would be. It was also hypothesized that habit automaticity would uniquely contribute to the efficacy of gratitude intervention. As an exploratory study, an array of outcome measures as suggested in previous gratitude intervention studies would be included.

\section{The process of habit formation and retention}

In a real-life 84-day study that encouraged participants to form new habits of health behaviours (eating fruit, drinking water, exercising) by daily repetition and reporting of habit strength (Lally et al., 2010), the trajectory with which habit automaticity consolidates was 
proposed to follow an asymptotic curve. In other words, habit automaticity increased with a gradually smaller amount with each repetition until it reached a plateau. Being theoretically more meaningful than a linear model, its parameters also informed the rate of habit formation and time needed in formation.

This finding has only been demonstrated in habit formation of simple behaviours. Complex activities took longer time in habit formation (Wood et al., 2002). Whether the asymptotic model in habit formation could be applied to more complex mental activities remained a question unanswered. The current study bore a close replication of methodology in Lally et al. (2010)'s study to answer the question. Additionally, to bring new understanding to the lifecycle of habits, this study would also explore, from repeated follow-up measures, what contributed to the maintenance of habit automaticity.

\section{Method}

\section{Design}

The current exploratory study consisted of a single arm 84-day intervention with three post-intervention assessments, at the end of the intervention period, and 4 weeks and 12 weeks thereafter. Procedure was visualized at Figure 1. All participants were initially led to do a 1-minute gratitude thinking exercise (see supplemental online materials for standardized script). They were encouraged to do gratitude thinking before they slept every night. During the 84-day period, participants had to report whether they have practised gratitude in the prior 
night and complete the automaticity subscale of SRHI. Emphasis was made to participants that the study participation cash reward was only contingent to their compliance in reporting but not in gratitude practices. Mixed methods were employed in outcome measures.

\section{Participants}

Upon university mass email invitation, 211 participants were invited to the initial meeting after they reported online having no habit of gratitude thinking before sleeping. Some declined to participate due to the commitment required. 180 signed consent form to participate the intervention phase. The sample size, determined before analysis, almost doubled Lally et al (2010)'s, in view of the higher complexity of activity in this study which might make the trend of habit formation within 84 days less conspicuous. All participants who attended the post-intervention meeting would be further invited to participate the follow-up phase of the study by email invitations.

\section{Quantitative measures}

Affect

Participants reported to what extent they generally feel each affect with a 5-point Likert scale ranging from "very slightly or not at all" to "extremely" for 30 affect items in resemblance to the Watson, Clark, \& Tellegen (1988) study. The items made up positive affect (PA) and negative affect (NA) subscales. Three of them (grateful, thankful, appreciative) made up the Gratitude Affect Checklist (GAC) subscale (Froh et al., 2009). 


\section{Dispositional gratitude}

Gratitude Questionnaire-Six (GQ-6; McCullough et al., 2002) was used. The instrument had six items and used a 7-point Likert scale from strongly disagree to strongly agree.

\section{Life satisfaction}

Satisfaction with life scale (SWLS; Diener, Emmons, Larsen, \& Griffin, 1985) was adopted. The 5-item SWLS assessed life satisfaction in general and also the subjective cognitive appraisal of well-being. It had a 7-point Likert scale ranged from "strongly disagree" to "strongly agree".

\section{Happiness}

Subjective Happiness Scale (SHS; Lyubomirsky \& Lepper, 1999) was used to measure the level of subjective happiness of participants. The 4-item SHS has a 7-point Likert scale for each item.

\section{Prosocial behavior}

Two "Yes" or "No" questions from Froh et al. (2009) were used: "Have you helped someone with a problem since yesterday?" and "Have you offered someone emotional support since yesterday?".

Social Support

A 2-item (Froh et al., 2009) 5-point Likert scale (from "not very supportive" to "very supportive") was used: "How supportive is your family?" and "How supportive are your 
friends?"

Hostility

A "Hostility Cognition" subscale in the Chinese Hostility Inventory (Lin \&Weng, 2002) was adopted in this study. It consisted of 10 items in a 5-point Likert scale, from "totally disagree" to "'totally agree".

Subjective habit formation

The two 'yes/no' questions were asked to see if participants regarded themselves as having formed a habit of gratitude thinking in general and at the specific context of before sleeping.

Habit and habit automaticity

SRHI, a 12-item questionnaire with a 7-point Likert scale, was used in assessing habit and habit automaticity. To fit the objective of this study, SRHI was adapted to start with "Gratitude thinking before sleeping is something..." followed by 12 items covering the frequency (e.g. "I do frequently"), automaticity (e.g. "I do without thinking”) and identification (e.g. "that is typically 'me."”) Habit was assessed by completing the full scale. A 7-item automaticity subscale was used similar to Lally et al.’s (2010) study.

To assess the habit strength on doing online daily questionnaire, SRHI was administered starting with "Doing the daily online questionnaire for this study is something..." followed by the same 12 items. 


\section{Qualitative measures}

In all the meetings, participants were invited to write a short paragraph to describe the content of their gratitude thinking practice. At the post-intervention meeting, they were also asked to write a short paragraph on why they thought they had or had not formed a habit of gratitude thinking before sleeping.

\section{Analysis on the potential efficacy of intervention and its maintenance}

Composite scores of affects would be computed for further analysis following factor structure produced from exploratory factor analysis with pre-test data and confirmatory factor analysis with post-test data (available at supplemental online materials).

Paired t-test on pre- and post-intervention outcome measures were conducted to explore whether they significantly changed during the 84-days of intervention. By hierarchical multiple regression, the significantly changed psychological well-being measures would be regressed on dispositional gratitude, the number of questionnaires filled, habit automaticity of questionnaire filling, number of repetition of gratitude thinking, and habit automaticity of gratitude thinking before sleeping, to investigate how different components of commitment in the study contributed to the change of these well-being measures.

To explore whether changes of outcome measures were sustained at follow-up, longitudinal linear mixed modelling would be done using data collected from post-study, 4-week and 12-week follow-up. Qualitative data would be coded to complement analyses on 
the above.

\section{Analysis on habit formation}

In SPSS version 18, non-linear regression was conducted to produce a curve for each individual's data. Mitscherlich's law of diminishing returns $\left(y=a-b e^{-c x}\right)$ was used in the modeling of mental habit, where $\mathrm{y}$ is the habit strength and $\mathrm{x}$ is the number of repetition/day of study (Mitscherlich, 1919). Constants 'a', 'b' and 'c' all have psychologically relevant meaning: 'a' represents the asymptote of the habit strength, the peak automaticity achievable, ' $b$ ' is the difference between the asymptote and the baseline score, and ' $c$ ' is the rate constant that represent the rate reaching the asymptote. The Akaike Information Criterion (AIC; Akaike, 1974; see Burnham \& Anderson, 2001 for brief review) was calculated for every participant on the nonlinear model and linear model for model comparison (Wagenmakers \& Farrell, 2004).

\section{Analysis on maintenance of habit and frequency of gratitude thinking}

With repeated data collection at follow up periods, longitudinal linear mixed modelling would be done using post-study habit automaticity score collected at post-study meeting as independent variable, and number of times of gratitude thinking before sleeping at the week before the two follow-up meetings as dependent variables. Coefficients computed could determine the level of automaticity needed to allow the sustained performance of gratitude thinking before sleeping. 


\section{Results}

\section{Descriptive statistics}

The 180 participants ( 89 men, 91 women) were predominantly Chinese undergraduates with a mean age of 20.39 (range 17 - 25). 155 participants completed the post-test after the 84-day intervention. 123 participants provided enough data (deemed 21 days of habit automaticity data and 21 repetition of gratitude thinking) during the 84 days for analysis of habit formation. Only 38 and 50 participants attended the 4-week and 12-week follow-up respectively. Among them, 10 of them attended both meetings.

\section{Validity of habit automaticity in subjective formation of habit of gratitude thinking}

Participants' self report on whether they have formed the habit of gratitude thinking before sleeping was logistically regressed on the SRHI total score at the end of the 84-day intervention. The effect was found to be significant $(\hat{\beta}=.113, \mathrm{~W}=40.49, p<.001)$. The unique contribution of habit automaticity was supported as an alternative model with number of repetitions, habit automaticity and their interaction as independent variables was a significantly better model (change of chi-square $=32.74$, change of $\mathrm{df}=2, \mathrm{p}<.001$ ). For every 1 -unit increase in habit automaticity, the probability of a participant self-reporting such a habit would be increased by a multiplicative factor of 1.185 , controlling the same number of repetition.

\section{Change in psychological well-being measures after the 84-day intervention}


Table 1 shows the result of the paired t-test between pre- and post-test data and longitudinal mixed model on data from all timepoints. In t-tests, after Bonferroni correction for multiple testing, participants showed significantly increased SWLS and GAC, and significant decreased NA and hostility.

Table 2 shows the correlation between repetition, compliance rate, and different changes in outcome measures. To test the hypothesis that habit automaticity contributed uniquely to the improvements of well-being, post-intervention well-being was regressed on age, gender, religion, respective pre-test well-being scores, interaction of repetition of gratitude thinking and pre-test dispositional gratitude, and habit automaticity in a four-step hierarchical multiple regression. In addition to SWLS, hostility, NA and GAC, PA and GQ-6 were also included as independent variables as they had both showed significant positive correlations with number of repetitions and habit automaticity of nightly gratitude thinking. Results shown at Table 3 suggested different critical determinants in the change in different outcome measures (details on assumptions checking available at supplementary online materials). It was shown in Step 4 that habit automaticity uniquely contributed to the prediction of changes in SWLS, PA, GAC and GQ-6 over and above the previously entered variables. Conversely, results suggested that only the repetition of gratitude thinking significantly contributed to the improvement of hostility. Dispositional gratitude mostly had an insignificant role on the improvements of well-being measures except for GAC. 


\section{Habit formation: model Comparison}

Participants' individual scatter plots with HIGT automaticity scores over days were generated (examples shown in Figure 2). By visual inspection it was seen that many plots had the automaticity scores increasing along with days in the expected curve shape, confirming the appropriateness to run nonlinear regression to fit asymptotic curves. In nonlinear regression, to prevent meaningless estimated results of parameters, 'a' and 'b' were constrained to be equal to or less than 49 , which was seven points more than the maximum value of the original 0 - 42 range. Four participants were excluded because their automaticity did not change throughout 84 days. AIC values of nonlinear model or linear model were computed for each participant. One participant with outlying nonlinear regression AIC (with +3 SD) and 24 participants showing unchanging or decreasing trends of habit formation was further removed. Paired t-test revealed AIC values in the two models were not significantly different; $\mathrm{t}(93)=0.36, \mathrm{p}=.72$.

In the 94 participants remained, median $\mathrm{R}^{2}$ value for these participants was .63 (Q1:Q3 $=0.19: 0.83$ ). The distribution of $\mathrm{R}^{2}$ was plotted in Figure 3. A step-change was seen in the frequency of participants with $\mathrm{R}^{2}$ values above .6 and therefore it was used as the threshold. Other 44 participants had $\mathrm{R}^{2}$ value below .6, suggesting a different pattern than the nonlinear model.

The asymptote curve nonlinear model was therefore a good fit for 50 out of 94 
participants $(53 \%)$ who showed a trend of habit formation. Figure 4 shows examples of the modeled curves of three participants.

Table 4 shows variables related to commitment to the study, performance variables and last automaticity score reported. Participants in the 'good fit' group had statistically more repetitions of gratitude thinking before sleeping than the other groups. Unsurprisingly, participants who did not show a trend of habit formation had significantly lower automaticity score reported after 84 days. Paired t-test comparing AIC values showed nonlinear model being superior, $\mathrm{t}(49)=2.55, \mathrm{p}=.014$.

\section{Role of intrinsic motivation in habit formation}

Qualitative data from participants on their self understanding on why habits were or were not formed by the end of the 84-day intervention were analyzed. A coding scheme was created by inspecting emerging themes of participants' responses. Examples of codes were external reward ("I am paid for the study"), compliance ("because the researcher asked me to"), and intrinsic motivation ("I felt happy after gratitude thinking"). Two researchers independently coded the responses with interrater reliability Kappa at an acceptable level of .74. Discrepancies in coding were resolved through discussion. The responses were collapsed into a binary code indicating whether intrinsic motivation was present or not because other reward and punishments were absent after the 84-day intervention and that intrinsic motivation was suggested to influence habit formation (Gardner \& Lally, 2013). 
As shown in Table 3, regression results on habit automaticity, done similarly as the regressions on well-being measures except entering intrinsic motivation instead at Step 4, revealed that presence of intrinsic motivation significantly predicted higher automaticity.

\section{Habit automaticity as a mediator to improvement of SWLS, GAC and GQ-6}

Knowing habit automaticity was predicted by number of repetitions and improvements in SWLS, PA, GAC and GQ-6 were uniquely predicted by habit automaticity while controlling effect of number of repetition, mediation analyses were conducted to determine whether habit automaticity was a mediator to improvements of them. With a sample size of 155, unstandardized indirect effects were computed for each of 5,000 bootstrapped samples. Bootstrapped unstandardized indirect effects were significant for SWLS, GAC and GQ-6, at $.022(95 \%$ confidence interval 002 to .047$), \mathrm{p}=.032, .013(95 \%$ confidence interval.005 to .021$), \mathrm{p}=.002$, and $.020(95 \%$ confidence interval.004 to .040$), \mathrm{p}<.05$ respectively. Bootstrapped unstandardized indirect effect was .002 (95\% confidence interval ranged from -.000 to .005 ) for increases in PA, statistically insignificant at $\mathrm{p}=.06$. Results were visually summarized at Figure 5.

\section{Maintenance of improvements on outcome measures}

Linear mixed model was used to understand the changes of different outcome measures over the 12 weeks of follow-up. Intercepts for participants and by-participant random slopes for the effect of time were input as random effects for the model. The interaction of habit 
automaticity and time was entered as fixed effects in the model. Significance of coefficients were obtained by likelihood ratio tests on step-wise comparisons from intercept-only simple linear models to the full mixed models. Results were shown in Table 5. None showed a significant improvement of model fit upon adding time or interaction of time and habit automaticity as fixed effect after controlling random intercepts as random effects, though habit automaticity at post-intervention was significantly contributing to the maintenance of higher GAC throughout follow-ups. To follow up on the non-significant result on time effect, an equivalence test was conducted by paired t-test between post-intervention data and follow-up data by conservatively treating all of them collected at the same 4-week follow-up snapshot. Table 1 showed that, as indicated by the $90 \%$ confidence interval of the effect sizes, changes in NA and GAC were of none to small effect that was up to only half of the changes from the intervention period. This could be conservatively interpreted as that there were no significant changes in NA and GAC in 4 weeks.

Maintenance of self-initiated gratitude thinking and habit automaticity after intervention period

As shown in Table 5, linear mixed model showed that HIGT automaticity score at post-study meeting significantly predicted the number of repetition at 4 -week and at 12 -week follow-up. Using $\beta$ produced, automaticity score required to maintain a certain level of frequency of gratitude thinking before sleeping could be computed. Four repetitions in a 
week were determined as maintenance of habit as it was "more often than not". On average, the automaticity scores required were 30 and 34 respectively for maintenance after 4 weeks and 12 weeks.

For habit automaticity, there was a significant trend of decrease of automaticity over the weeks in follow-up period. Presence of intrinsic motivation was significantly contributing to higher habit automaticity with the effect of weeks elapsed controlled. Introducing number of nightly gratitude thinking and its interaction with weeks elapsed as fixed effect both further significantly improved the model. In the full model, $\beta$ of weeks elapsed has become less important.

\section{Discussion}

This exploratory single-arm study used a novel approach of gratitude intervention by specifying habit formation as the intervention target. For the majority of participants, habit automaticity increased over the 84 days of intervention period in an asymptotic manner. Psychological well-being measures, specifically satisfaction with life, gratitude affect, negative affect and hostility, have improved over the 84 days. Improvements in negative affects and gratitude affects have maintained for at least 4 weeks of follow-up.

\section{Efficacy of the new gratitude intervention}

Due to the single-arm study design, the efficacy of the intervention programme per se was not backed by statistical inference. Improvements in psychological well-being could 
have been due to other reasons, for instance a cohort effect in the 155 participants who were generally happier after the exam season in the first few weeks of the 84-day intervention. However, participants' daily practices of gratitude thinking before sleeping and the increase of its habit automaticity, which significantly predicted improvements in outcome measures, were very likely resulted from the study's requirements, as only participants who reported no such habits in the past were recruited. Therefore, the current approach of intervention with a focus on building a habit could be argued as having some positive influence on SWLS, hostility, PA, GAC, GQ-6, and, with less certainty, on NA

Number of repetitions in gratitude thinking and habit automaticity were found to have uniquely contributed to different improvements and their maintenance. These differences suggested that the mechanisms of how gratitude intervention affected each outcome measure could be different. Specifically, habit automaticity mediated the effect of gratitude thinking practices in the improvements of SWLS, GAC, and GQ-6.

To practitioners, these results highlighted the importance of cultivating the habit of gratitude thinking in participants beyond just encouraging them to practice repeatedly. To achieve better efficacy, gratitude interventions should also be carried out in ecologically valid contexts with relatively stable cues so that participants were more likely to be habitual in gratitude thinking.

The current findings showed an insignificant role of habit automaticity in changes of NA 
and hostility, both negative-valence constructs. Many hypotheses are possible for further research on how repetition of gratitude thinking affected these constructs, for example downregulation of unpleasant emotions, enhanced cognitive flexibility in interpreting daily events in positive lights (Quoidbach et al. 2015), or a cognitive appraisal on the resourcefulness in one's life through gratitude thinking.

The dosage of gratitude intervention on each occasion of practice in this study was less than that of most of the previous studies on gratitude intervention. In this study, only contemplation of less than a minute on one incident was involved, whereas in many previous studies participants were asked to recall incidents and write them on papers. Given a longer intervention period in this study, it is difficult to determine if the "overall dosage" in this study was more or less than other studies of gratitude intervention. Nevertheless, it is still encouraging to know that this novel approach of gratitude intervention was potentially efficacious while being less effort-taxing to participants in each practice

\section{Reciprocal relationship between repetition and automaticity}

Number of repetitions of gratitude thinking before sleeping and intrinsic motivation, measured from daily quantitative reporting and end-of-intervention qualitative response respectively, independently contributed to higher habit automaticity after 84 days. Habit automaticity in turn predicted maintained frequency in self-initiated gratitude thinking as reported in follow-up questionnaires. Closing the loop, such frequency significantly 
facilitated the maintenance of high habit automaticity as reported in the follow-up phase, counteracting the effect of weeks elapsed since the end of intervention period. Taking the above findings together, frequency of gratitude thinking before sleeping and its habit automaticity could be seen as reciprocally reinforcing each other. While the current data supported intrinsic motivation having added impetus to the cycle above, the study's text message reminders, in combination with participants' extrinsic motivations, such as tendency to fulfill the study's requirement or monetary reward, could have contributed to kick-starting the frequency-automaticity positive feedback loop. As habit formation is highly context dependent, the study's ecologically-valid context of intervention might have also facilitated participants' maintenance of habit in the 12 weeks of follow-up.

\section{Time taken in forming a habit of gratitude thinking}

Knowing that more complex activity takes longer to become habitual, the gratitude intervention in this study was purposely designed with limited complexity, so that changes in the habit formation process over 84 days were observable. The habit formation process in gratitude thinking was observed to follow an asymptotic curve, as found in a previous study that investigated habit formation in simple behaviours (Lally et al., 2010). This replication of finding favored the hypothesis that the asymptotic curve could describe processes of habit formation beyond that of simple behaviours.

It was estimated that the median days for participants to reach the plateau of a habit of 
gratitude thinking was 187 days, a number much larger than 66 days in simple behavioural habits. Upon 110 days of practice, half of the participants could reach an automaticity score of 30 which was high enough for an average participant to sustain a frequency of gratitude thinking for 4 weeks after intervention. It is important to note that the current study did not provide extrinsic reward nor emphasize possible intrinsic motivation from practicing gratitude thinking. With provision of these, together with practical tips on habit formation for participants, it is possible to shorten the number of days needed to form such a habit.

\section{Limitations}

The single-arm study design and rather homogenous population from the university were major limitations in this study, limiting the generalizability of current findings. Second, despite effort in standardizing the gratitude thinking procedure, individual differences in dosage of the intervention, in terms of duration spent and complexity of gratitude thinking, was not well controlled nor measured. Those who chose to spend more time and effort on gratitude thinking might have experienced a higher emotional arousal (Bower, 1992), potentially increasing the intrinsic motivation on each practice. Third, irregularity in both sleeping time and location, as qualitatively reported by some participants, were not captured for the analysis of habit formation. Fourth, while dispositional gratitude has been a factor being controlled for, other individual differences, such as participants' tendency to comply with study requirements or openness to new experience, might have been confounding 
variables for the current findings on efficacy. Lastly, results on the maintenance of efficacy

had a small power due to small sample size in follow-up phase. Interpretation on these results were further complicated by the explanation of possible benefits of gratitude thinking during debriefing of the intervention phase.

Further experimental studies with a wider population base are needed to replicate the current findings and discover other factors that affected the habit formation of gratitude thinking and its potential efficacy.

\section{Conclusion}

Despite these caveats, this research demonstrated the potential of an efficacious gratitude intervention by including habit formation as part of the target of gratitude intervention. Without having explicitly stated the potential benefits of gratitude thinking nor extrinsic reward contingent to such practice, repetitions in gratitude thinking in a consistent real-life context, namely before sleeping, appeared to be enough for many to develop habit automaticity for it. Following an asymptotic pattern of increment, habit automaticity predicted continued nightly gratitude thinking after intervention period, which in turn predicted maintenance of a high level of automaticity. It was indicatively shown that habit automaticity mediated the improvements in life satisfaction, grateful affects and dispositional gratitude. In the follow-up phase, there was some support that improvements in some well-being measures, notably negative and grateful affects, were maintained. Overall, 
targeting habit automaticity in gratitude intervention, or even in other mental health interventions, seemed to be a promising approach for further research and eventual utilization by mental health practitioners. 


\section{References}

Akaike, H. (1974). A new look at the statistical model identification. IEEE Transactions on Automatic Control, 19, 716-723.

Balleine, B. W., \& O'doherty, J. P. (2010). Human and rodent homologies in action control: corticostriatal determinants of goal-directed and habitual action. Neuropsychopharmacology, 35(1), 48-69.

Boehm, J. K., Lyubomirsky, S., \& Sheldon, K. M. (2011). A longitudinal experimental study comparing the effectiveness of happiness-enhancing strategies in Anglo Americans and Asian Americans. Cognition \& Emotion, 25(7), 1263-1272.

Bower, G. H.. How might emotions affect learning? In: Christianson S-A, editor. The Handbook of Emotion and Memory: Research and Theory. Erlbaum; Hillsdale, NJ: 1992. pp. 3-31.

Burnham, K. P., \& Anderson, D. R. (2001). Kullback-Leibler information as a basis for strong inference in ecological studies. Wildlife Research, 28, 111-119.

Carman, J. B., \& Streng, F. J. (1989). Spoken and unspoken thanks: Some comparative soundings. Dallas, TX: Center for World Thanksgiving.

Dickinson, A., Balleine, B., Watt, A., Gonzalez, F., \& Boakes, R. A. (1995). Motivational control after extended instrumental training. Animal Learning \& Behavior, 23(2), 197-206. 
Diener, E. D., Emmons, R. A., Larsen, R. J., \& Griffin, S. (1985). The satisfaction with life scale. Journal of personality assessment, 49(1), 71-75.

Dossett, T. H. (2011). The influence of the character strengths of gratitude and kindness on subjective well-being.

Emmons, R. A., \& McCullough, M. E. (2003). Counting blessings versus burdens: an experimental investigation of gratitude and subjective well-being in daily life. Journal of Personality and Social Psychology, 84(2), 377-389.

Froh, J. J., Kashdan, T. B., Ozimkowski, K. M., \& Miller, N. (2009). Who benefits the most from a gratitude intervention in children and adolescents? Examining positive affect as a moderator. The journal of positive psychology, 4(5), 408-422.

Galla, B. M., \& Duckworth, A. L. (2015). More than resisting temptation: Beneficial habits mediate the relationship between self-control and positive life outcomes. Journal of personality and social psychology, 109(3), 508.

Gardner, B. (2015). A review and analysis of the use of 'habit' in understanding, predicting and influencing health-related behaviour. Health psychology review, 9(3), 277-295.

Gardner, B., \& Lally, P. (2013). Does intrinsic motivation strengthen physical activity habit? Modeling relationships between self-determination, past behaviour, and habit strength. Journal of behavioral medicine, 36(5), 488-497.

Geraghty, A. W., Wood, A. M., \& Hyland, M. E. (2010). Attrition from self-directed 
interventions: Investigating the relationship between psychological predictors, intervention content and dropout from a body dissatisfaction intervention. Social Science \& Medicine, 71(1), 30-37.

Hogarth, L., \& Chase, H. W. (2011). Parallel goal-directed and habitual control of human drug-seeking: Implications for dependence vulnerability. Journal of Experimental Psychology: Animal Behavior Processes, 37(3), 261.

Hull, C. L. (1943). Principles of behavior (Vol. 422). New York: Appleton-century-crofts.

Kerr, S. L., O’Donovan, A., \& Pepping, C. A. (2015). Can gratitude and kindness interventions enhance well-being in a clinical sample?. Journal of Happiness Studies, 16(1), 17-36.

Lally, P., Van Jaarsveld, C. H., Potts, H. W., \& Wardle, J. (2010). How are habits formed: Modelling habit formation in the real world. European journal of social psychology, 40(6), 998-1009.

Lin, I. M., \& Weng, C. Y. (2002). Relationship between hostility pattern and psychophysiological disorders: cases of coronary artery disease and headache. Chinese Journal of Psychology, 44(2), 211-226.

Lyubomirsky, S., \& Lepper, H. S. (1999). A measure of subjective happiness: Preliminary reliability and construct validation. Social indicators research, 46(2), 137-155.

McCullough, M. E., Emmons, R. A., \& Tsang, J. A. (2002). The grateful disposition: a 
conceptual and empirical topography. Journal of personality and social

psychology, 82(1), 112.

Mitscherlich, E. A. (1919). Zum Gesetz des Pflanzenwachstums. Fuhlings

landwirtschaftliche Zeitung, 21-22, 419-426.

Quoidbach, J., Mikolajczak, M., \& Gross, J. J. (2015). Positive interventions: An emotion regulation perspective. Psychological bulletin, 141(3), 655.

Rash, J. A., Matsuba, M. K., \& Prkachin, K. M. (2011). Gratitude and well-being: Who benefits the most from a gratitude intervention?. Applied Psychology: Health and Well-Being, 3(3), 350-369.

Roberts, R. C. (2004). The blessings of gratitude: A conceptual analysis. The psychology of gratitude, 58-78.

Verhoeven, A. A., Adriaanse, M. A., Evers, C., \& de Ridder, D. T. (2012). The power of habits: Unhealthy snacking behaviour is primarily predicted by habit strength. British journal of health psychology, 17(4), 758-770.

Verplanken, B., Friborg, O., Wang, C. E., Trafimow, D., \& Woolf, K. (2007). Mental habits: Metacognitive reflection on negative self-thinking. Journal of personality and social psychology, 92(3), 526.

Verplanken, B., \& Orbell, S. (2003). Reflections on past behavior: A self-report index of habit strength. Journal of Applied Social Psychology, 33(6), 1313-1330. 
Wagenmakers, E., \& Farrell, S. (2004). AIC model selection using Akaike weights.

Psychonomic Bulletin and Review, 11(1), 192-196.

Watkins, E. R., \& Nolen-Hoeksema, S. (2014). A habit-goal framework of depressive rumination. Journal of Abnormal Psychology, 123(1), 24.

Watson, D., Clark, L. A., \& Tellegen, A. (1988). Development and validation of brief measures of positive and negative affect: the PANAS scales. Journal of personality and social psychology, 54(6), 1063.

Wood, A. M., Joseph, S., \& Maltby, J. (2009). Gratitude predicts psychological well-being above the Big Five facets. Personality and Individual differences, 46(4), 443-447.

Wood, W., Quinn, J. M., \& Kashy, D. A. (2002). Habits in everyday life: Thought, emotion, and action. Journal of Personality and Social Psychology, 83, 1281-1297. 
Table 1

Results of Paired Tests on Different Outcome Measures Between Different Time Points

\begin{tabular}{|c|c|c|c|c|c|c|c|c|c|}
\hline & \multicolumn{4}{|c|}{$\begin{array}{l}\text { Pre- and post-intervention comparison } \\
\qquad(\mathrm{n}=155)\end{array}$} & \multicolumn{5}{|c|}{$\begin{array}{l}\text { Post-intervention and follow-up comparison } \\
\qquad(\mathrm{n}=60)\end{array}$} \\
\hline & $\operatorname{Mean}(\mathrm{SD})^{\mathrm{a}}$ & $t$ & $p^{b}$ & $\begin{array}{c}\text { Cohen's } \\
d\end{array}$ & Mean $(\mathrm{SD})^{\mathrm{a}}$ & $t$ & $p^{b}$ & $\begin{array}{c}\text { Cohen's } \\
d\end{array}$ & $\begin{array}{c}90 \% \\
\text { Confidence } \\
\text { Interval of } d\end{array}$ \\
\hline PA & $\begin{array}{l}3.12(0.56) \\
3.14(0.58)\end{array}$ & 0.44 & .663 & 0.035 & $\begin{array}{l}3.15(0.54) \\
3.09(0.66)\end{array}$ & -0.88 & .382 & -0.097 & {$[-0.279,0.082]$} \\
\hline NA & $\begin{array}{c}2.7(0.65) \\
2.37(0.64)\end{array}$ & -7.10 & $.000 * *$ & -0.565 & $\begin{array}{l}2.31(0.59) \\
2.31(0.71)\end{array}$ & 0.05 & .958 & 0.006 & {$[-0.193,0.206]^{\#}$} \\
\hline GAC & $\begin{array}{c}9.28(2.2) \\
10.19(2.24)\end{array}$ & 3.88 & $.000 * *$ & 0.312 & $\begin{array}{l}10.22(2.14) \\
10.18(2.04)\end{array}$ & -0.19 & .848 & -0.020 & {$[-0.192,0.151]^{\#}$} \\
\hline GQ & $\begin{array}{l}30.01(4.43) \\
30.37(4.57)\end{array}$ & 1.33 & .186 & 0.105 & $\begin{array}{l}30.55(4.16) \\
29.67(3.99)\end{array}$ & -2.26 & .030 & -0.215 & {$[0.379,-0.058]$} \\
\hline SWLS & $\begin{array}{l}20.35(5.57) \\
21.86(5.62)\end{array}$ & 4.26 & $.000 * *$ & 0.337 & $\begin{array}{l}22.05(5.23) \\
22.42(5.33)\end{array}$ & 0.75 & .459 & 0.069 & {$[-0.085,0.225]$} \\
\hline SHS & $\begin{array}{r}16.98(4.1) \\
17.66(4.14)\end{array}$ & 2.51 & .013 & 0.203 & $\begin{array}{l}18.08(4.01) \\
18.65(4.68)\end{array}$ & 1.35 & .183 & 0.129 & {$[-0.027,0.289]$} \\
\hline Self Esteem & $\begin{array}{l}27.68(4.21) \\
28.14(4.18)\end{array}$ & -1.98 & .050 & 0.110 & $\begin{array}{c}28.6(4.69) \\
28.63(4.55)\end{array}$ & 0.33 & .939 & 0.005 & {$[-0.112,0.123]$} \\
\hline Prosocial Behavior & $\begin{array}{l}1.38(0.71) \\
1.31(0.71)\end{array}$ & 1.03 & .304 & -0.089 & $\begin{array}{l}1.42(0.67) \\
1.27(0.78)\end{array}$ & -1.42 & .161 & -0.205 & {$[-0.450,0.034]$} \\
\hline Social Support & $\begin{array}{l}8.38(1.44) \\
8.3(1.33)\end{array}$ & -0.96 & .341 & -0.074 & $\begin{array}{l}8.28(1.22) \\
8.15(1.42)\end{array}$ & -0.82 & .414 & -0.100 & {$[-0.302,0.100]$} \\
\hline Hostility & $\begin{array}{l}28.99(6.85) \\
27.26(6.59)\end{array}$ & -4.32 & $.000 * *$ & -0.352 & $\begin{array}{c}26(6.32) \\
27.17(6.6)\end{array}$ & 2.08 & .042 & 0.179 & {$[0.037,0.327]$} \\
\hline HIGT (all) & $\begin{array}{c}27.63(14.14) \\
41.82(19.5)\end{array}$ & 9.01 & $.000 * *$ & 0.748 & $\begin{array}{l}44.48(20.27) \\
36.68(18.09)\end{array}$ & -4.70 & $.000 * *$ & -0.403 & {$[-0.557,-0.261]$} \\
\hline HIGT (automaticity) & $\begin{array}{c}17.12(9.17) \\
24.25(11.74)\end{array}$ & 7.36 & $.000 * *$ & 0.604 & $\begin{array}{l}26.07(12.06) \\
22.05(10.68)\end{array}$ & -3.99 & $.000 * *$ & -0.350 & {$[-0.505,-0.205]$} \\
\hline & $\operatorname{Mean}(\mathrm{SD})^{\mathrm{a}}$ & Chi-sq & $p^{c}$ & & $\operatorname{Mean}(\mathrm{SD})^{\mathrm{a}}$ & Chi-sq & $p^{c}$ & & \\
\hline $\begin{array}{l}\text { General Gratitude } \\
\text { Thinking Habit }\end{array}$ & $\begin{array}{l}0.65(0.48) \\
0.66(0.48)\end{array}$ & 0.00 & 1.000 & & $\begin{array}{l}0.72(0.45) \\
0.53(0.5)\end{array}$ & 5.88 & .015 & & \\
\hline $\begin{array}{l}\text { Gratitude Thinking } \\
\text { before sleeping Habit }\end{array}$ & $\begin{array}{l}0.00(0.00) \\
0.36(0.48)\end{array}$ & 97.01 & $.000 * *$ & & $\begin{array}{c}0.45(0.5) \\
0.23(0.43)\end{array}$ & 9.60 & $0.002 *$ & & \\
\hline
\end{tabular}


Table 2

Correlations between differences of gratitude and well-being related outcome measures, commitment to study, and habit related measures ( $N=155)$

\begin{tabular}{|c|c|c|c|c|c|c|c|c|c|c|c|c|c|c|c|c|}
\hline & & 1 & 2 & 3 & 4 & 5 & 6 & 7 & 8 & 9 & 10 & 11 & 12 & 13 & 14 & 15 \\
\hline 1 & PA difference & - & & & & & & & & & & & & & & \\
\hline 2 & NA difference & .09 & - & & & & & & & & & & & & & \\
\hline 3 & GAC difference & $.56 * * *$ & .03 & - & & & & & & & & & & & & \\
\hline 4 & GQ difference & $.26 * *$ & -.14 & $.31 * * *$ & - & & & & & & & & & & & \\
\hline 5 & SWLS difference & $.34 * * *$ & -.15 & $.23 * *$ & $.25 * *$ & - & & & & & & & & & & \\
\hline 6 & SHS difference & .13 & $-.23 * *$ & $.27 * * *$ & $.24 * *$ & $.37 * * *$ & - & & & & & & & & & \\
\hline 7 & $\begin{array}{l}\text { Prosocial Behavior } \\
\text { difference }\end{array}$ & -.02 & .03 & -.03 & .02 & -.07 & .00 & - & & & & & & & & \\
\hline 8 & $\begin{array}{l}\text { Social Support } \\
\text { difference }\end{array}$ & .02 & -.06 & .11 & .12 & .01 & $.23 * *$ & .11 & - & & & & & & & \\
\hline 9 & Hostility difference & $-.20 *$ & .07 & $-.25 * *$ & -.11 & $-.20 *$ & $-.34 * * *$ & .13 & .04 & - & & & & & & \\
\hline 10 & Self Esteem & $.20 *$ & $-.18 *$ & .11 & $.38 * * *$ & $.25 * *$ & $.23 * *$ & .10 & .05 & -.09 & - & & & & & \\
\hline 11 & $\begin{array}{l}\text { Number of online } \\
\text { auestionnaire entries }\end{array}$ & -.13 & .00 & -.11 & -.05 & -.07 & -.12 & -.01 & -.12 & -.09 & $-.17 *$ & - & & & & \\
\hline 12 & $\begin{array}{l}\text { Number of gratitude } \\
\text { thinking before sleeping }\end{array}$ & $.21 * *$ & $-.17 *$ & $.30 * * *$ & $.24 * *$ & .06 & .16 & .00 & $.17 *$ & $-.20 *$ & .07 & .05 & - & & & \\
\hline 13 & GQ-6 (Pre-test) & -.07 & .02 & -.05 & $-.38 * * *$ & -.11 & -.02 & -.05 & -.07 & -.05 & -.13 & -.13 & .12 & - & & \\
\hline 14 & $\begin{array}{l}\text { SRHI (questionnaire) at } \\
\text { post-intervention }\end{array}$ & .11 & -.08 & .14 & .14 & .08 & .05 & -.04 & -.07 & -.12 & .01 & .07 & $.26 * *$ & .09 & - & \\
\hline 15 & $\begin{array}{l}\text { SRHI (gratitude) at } \\
\text { post-intervention }\end{array}$ & $.23 * *$ & -.16 & $.29 * * *$ & $.21 * *$ & $.16 *$ & .13 & -.03 & .12 & $-.17 *$ & .06 & -.06 & $.69 * * *$ & .27 & $0.50 * * *$ & - \\
\hline 16 & $\begin{array}{l}\text { Gratitude automaticity } \\
\text { at post-intervention }\end{array}$ & $.20 *$ & -.15 & $.28 * * *$ & $.19 *$ & .16 & .12 & -.05 & .11 & $-.17 *$ & .03 & -.07 & $.65 * * *$ & .28 & $0.50 * * *$ & $0.99 * * *$ \\
\hline
\end{tabular}

Note. Correlations involving Prosocial behavior, Hostility, and two gratitude habit measures were based on $N=154, N=151$ and $N=153$ respectively, because of missing data.

$* p<.05 . * * p<.01 . * * * p<.001$. 
Table 3

Results of Hierarchical Regression Analyses for various outcome measure $(n=155)^{a}$

Post-intervention collected

outcome measure as Dependent Variable ${ }^{b}$

\begin{tabular}{|c|c|c|c|c|c|c|c|}
\hline Independent Variable ${ }^{b}$ & SWLS & Hostility $^{\mathrm{c}}$ & PA & NA & GAC & GQ-6 & Automaticity \\
\hline \multicolumn{8}{|l|}{ Step 1: Demographics \& autocorrelation } \\
\hline$(\text { Intercept })^{\mathrm{d}}$ & 4.71 & 9.57 & $2.23 * * *$ & $1.60 *$ & $7.12 * * *$ & $32.70 * * *$ & 2.95 \\
\hline Age & 0.06 & -0.11 & 0.04 & -0.04 & -0.05 & -0.18 & 1.01 \\
\hline Gender $($ female $=0$, male $=1)$ & 0.41 & -0.41 & 0.12 & 0.05 & 0.48 & -0.34 & -0.46 \\
\hline Religion (has religion $=1$ ) & -0.21 & -0.89 & -0.05 & -0.15 & -0.31 & -0.59 & 1.00 \\
\hline Respective score at pre-test & $0.68 * * *$ & $0.70 * * *$ & $0.65 * * *$ & $0.59 * * *$ & $0.31 * * *$ & $0.61 * * *$ & $0.23 * *$ \\
\hline $\mathrm{R}^{2}$ & 0.49 & 0.55 & 0.45 & 0.37 & 0.32 & 0.45 & 0.19 \\
\hline $\mathrm{F}$ & $36.30 * * *$ & $45.94 * * *$ & $30.07 * * *$ & $22.36 * * *$ & $17.51 * * *$ & $30.72 * * *$ & $7.02 * * *$ \\
\hline \multicolumn{8}{|l|}{ Step 2: Dispositional gratitude \& repetitions } \\
\hline GQ-6 & -0.03 & -0.12 & 0.00 & -0.00 & $0.14 * * *$ & / & $0.42 *$ \\
\hline Number of repetitions & -0.00 & $-0.04 *$ & 0.00 & -0.00 & $0.02 * *$ & 0.02 & $0.22 *$ \\
\hline$\Delta \mathrm{R}^{2}$ & 0.00 & 0.03 & 0.04 & 0.02 & 0.21 & 0.05 & 0.31 \\
\hline$\Delta \mathrm{F}$ & 0.00 & $5.04 * *$ & $6.05 * *$ & 1.71 & $34.55 * * *$ & $14.77 * * *$ & $96.30 * * *$ \\
\hline Step 3: Interaction of terms from (2) & 0.00 & -0.00 & -0.00 & 0.00 & -0.00 & -0.00 & -0.00 \\
\hline$\Delta \mathrm{R}^{2}$ & 0.02 & 0.00 & 0.01 & 0.00 & 0.00 & 0.01 & 0.00 \\
\hline$\Delta \mathrm{F}$ & 3.71 & 0.00 & 3.50 & 0.29 & 0.56 & 2.29 & 0.18 \\
\hline \multicolumn{8}{|l|}{ Step 4: } \\
\hline Post-intervention habit automaticity & $0.08 *$ & 0.01 & 0.01 & 0.00 & $0.05 * * *$ & $0.07 * * *$ & \\
\hline Intrinsic motivation & & & & & & & $6.09 * *$ \\
\hline Final $\mathrm{R}^{2}$ & 0.53 & 0.58 & 0.51 & 0.39 & 0.56 & 0.52 & 0.53 \\
\hline$\Delta \mathrm{R}^{2}$ & 0.02 & 0.00 & 0.01 & 0.00 & 0.03 & 0.02 & 0.03 \\
\hline$\Delta \mathrm{F}$ & $4.42 *$ & 0.04 & $4.17 *$ & 0.04 & $11.38 * * *$ & $5.74 *$ & $9.28 * * *$ \\
\hline
\end{tabular}

a. regression coefficients were all from final step of the regression. They were not standardized for easier interpretation of results.

b. refer to Measures for the range of score of the scales.

c. $\mathrm{n}=153$ due to missing data

d. intercept were adjusted by the mean-centering of GQ-6 and number of repetitions.

$* \mathrm{p}<.05, * * \mathrm{p}<.01, * * * \mathrm{p}<.001$ 
Table 4

Participants' participation and parameters from linear and nonlinear regression (quartiles $Q_{1}: Q_{3}$ inside brackets)

\begin{tabular}{|c|c|c|c|c|c|}
\hline & $\begin{array}{c}\text { Good Fit } \\
\left(R^{2}>=0.6\right)\end{array}$ & $\begin{array}{l}\text { Bad Fit } \\
R^{2}<0.6\end{array}$ & $\begin{array}{l}\text { Modelling } \\
\text { Unsuitable }^{\mathrm{a}}\end{array}$ & $\begin{array}{c}\text { Modelling } \\
\text { Suitable }\end{array}$ & All \\
\hline$n$ & 50 & 44 & 24 & 94 & 118 \\
\hline Number of online questionnaire entries, median & $71(61: 78)$ & $63(54: 77)$ & $73(64: 76)$ & / & $70(58: 78)$ \\
\hline Number of reported repetitions, median & $66(53: 74)$ & $56(42: 70)^{\mathrm{b}}$ & $53(34: 74)^{\mathrm{b}}$ & / & $60(43: 72)$ \\
\hline Last HIGT automaticity score reported ${ }^{\mathrm{c}}$ & $26(18: 33)^{\mathrm{d}}$ & $23(20: 33)^{\mathrm{d}}$ & $12(5: 28)$ & / & $23(15: 32)$ \\
\hline Linear Regression $R^{2}$ & $0.78(0.67: 0.87)$ & $0.24(0.10: 0.47)$ & l & $0.62(0.26: 0.78)$ & / \\
\hline Nonlinear Regression $R^{2}$ & $0.82(0.74: 0.90)$ & $0.09(0.00: 0.37)$ & / & $0.63(0.12: 0.83)$ & / \\
\hline AIC difference between nonlinear and linear model ${ }^{\mathrm{e}}$ & $-0.72(-24.19: 5.55)$ & $2.28(-4.48: 31.35)$ & l & $2.23(-10.43: 6.58)$ & l \\
\hline a (asymptote) & $44.21(28.20: 49.00)$ & $30.28(21.48: 49.00)$ & / & $36.65(22.87: 49.00)$ & l \\
\hline $\mathrm{b}$ (change in habit strength/automaticity) & $37.75(22.26: 49.00)$ & $20.15(10.28: 35.46)$ & l & $31.93(15.6: 45.91)$ & / \\
\hline c (rate of change) & $0.013(0.008: 0.026)$ & $0.064(0.002: 14.786)$ & l & $0.016(0.006: 0.069)$ & 1 \\
\hline Time to reach $95 \%$ of asymptote (days) & $222(108: 367)$ & $41(1: 1362)$ & l & $187(33: 506)$ & l \\
\hline Time to reach HIGT automaticity score of 30 (days $)^{f}$ & $105(76: 214)$ & $363(27: 675)$ & l & $110(63: 414)$ & / \\
\hline
\end{tabular}

a. Referred to participants with negative a, negative or very small b, negative c, or almost no change of reported HIGT throughout 84 days.

b. Mann-Whitney tests showed significant differences every pair between the 'good fit' group and each of the labelled group, Benjamini and Hochberg correction applied

c. The HIGT automaticity score computed from post-study questionnaire, or, if participants did not attend post-study meeting, HIGT automaticity score from the last available entry of daily questionnaire

d. Mann-Whitney tests showed significant differences every pair between the 'nonlinear model unsuitable' group and each of the labelled group, Benjamini and Hochberg correction applied e. negative value denoted AIC of nonlinear model was smaller than that of linear model; in model comparison, a smaller AIC value was preferred.

f. $n=38$ given 12 participants' asymptote was lower than 30 for Good Fit group and $n=24$ in Bad Fit group due to the same reason. 
Table 5

Results of Linear Mixed Model for outcome measures from post-intervention to follow-ups $(n=60)^{a}$

\begin{tabular}{|c|c|c|c|}
\hline Dependent Variable and Independent Variables ${ }^{\mathrm{b}}$ & beta & standard error & Chi-square \\
\hline \multicolumn{4}{|l|}{ SWLS } \\
\hline 1. (Intercept) & 19.75 & 1.53 & \\
\hline 2R. Intercept by participant & & 4.34 & \\
\hline 2R. Week by participant & & 0.10 & \\
\hline 3F. Week & 0.14 & 0.1 & 0.29 \\
\hline 4F. Post-intervention habit automaticity & 0.09 & 0.05 & 1.88 \\
\hline 5F. Interaction of week and habit automaticity & -0.00 & 0.00 & 1.60 \\
\hline \multicolumn{4}{|l|}{ Hostility } \\
\hline 1. (Intercept) & 26.01 & 1.95 & \\
\hline 2R. Intercept by participant & & 5.70 & \\
\hline 3F. Week & 0.07 & 0.11 & 2.84 \\
\hline 4F. Post-intervention habit automaticity & 0.01 & 0.07 & 0.04 \\
\hline 5F. Interaction of week and habit automaticity & 0.00 & 0.00 & 0.02 \\
\hline \multicolumn{4}{|l|}{ NA } \\
\hline 1. (Intercept) & 2.16 & 0.18 & \\
\hline 2R. Intercept by participant & & 0.49 & \\
\hline 2R. Week by participant & & 0.03 & \\
\hline 3F. Week & 0.01 & 0.02 & 0.00 \\
\hline $4 \mathrm{~F}$. Post-intervention habit automaticity & 0.01 & 0.01 & 0.41 \\
\hline 5F. Interaction of week and habit automaticity & -0.00 & 0.00 & 0.92 \\
\hline \multicolumn{4}{|l|}{ GAC } \\
\hline 1. (Intercept) & 7.41 & 0.57 & \\
\hline 2R. Intercept by participant & & 1.35 & \\
\hline 3F. Week & 0.08 & 0.05 & 0.13 \\
\hline 4F. Post-intervention habit automaticity & 0.10 & 0.02 & $19.42^{* * *}$ \\
\hline 5F. Interaction of week and habit automaticity & -0.00 & 0.00 & 2.19 \\
\hline \multicolumn{4}{|l|}{ Habit Automaticity } \\
\hline 1. (Intercept) & 14.92 & 1.49 & \\
\hline 2R. Intercept by participant & & 5.94 & 71.53 \\
\hline 3F. Week & 0.11 & 0.13 & $11.46^{* * *}$ \\
\hline 4F. Intrinsic motivation & 3.94 & 2.02 & $6.89^{* *}$ \\
\hline 5F. Number of nights with gratitude thinking in last 7 days & 2.37 & 0.29 & $54.97 * * *$ \\
\hline $6 \mathrm{~F}$. Interaction of week and nights with gratitude thinking & -0.07 & 0.03 & $4.91 *$ \\
\hline \multicolumn{4}{|l|}{ Number of nights with gratitude thinking done in last 7 days $^{\mathrm{c}}$} \\
\hline 1. (Intercept) & -0.10 & 0.84 & \\
\hline 2R. Intercept by participant & & 1.91 & $19.64^{* * *}$ \\
\hline 3F. Week & -0.08 & 0.05 & 1.97 \\
\hline 4F. Post-intervention habit automaticity & 0.15 & 0.03 & $27.53^{* * *}$ \\
\hline
\end{tabular}

a. regression coefficients were all from final step of the regression. They were not standardized for easier interpretation.

b. indented are the effects added in different steps: $\mathrm{R}$ and $\mathrm{F}$ denote random and fixed effects respectively

c. adding intrinsic motivation as a fixed effect did not significantly improve the model 


\begin{tabular}{|c|c|c|c|c|c|c|c|c|c|}
\hline & \multirow{5}{*}{84 days } & & \multicolumn{3}{|c|}{ Interventions } & \multicolumn{4}{|c|}{ Measures } \\
\hline & & Event & $\begin{array}{c}\text { Standardized } \\
\text { Gratitude Thinking } \\
\text { Practice }\end{array}$ & Reward & Other Interventions & $\begin{array}{c}\text { Well-being- } \\
\text { related } \\
\text { quantitative } \\
\text { measures } \\
\end{array}$ & Qualitative responses & Habit & $\begin{array}{c}\text { Frequency of } \\
\text { nightly gratitude } \\
\text { thinking }\end{array}$ \\
\hline $\begin{array}{l}0 \\
\tilde{c} \\
\tilde{c}\end{array}$ & & Initial Meeting & $\begin{array}{l}\text { Compulsory, } \\
\text { led by researcher }\end{array}$ & \multirow{3}{*}{$\begin{array}{l}\text { Cash reward } \\
\text { contingent to filling } \\
\text { questionnaires only } \\
\text { (pre-test, post-test } \\
\text { and }>58 \% \text { of daily } \\
\text { questionnaire) but not } \\
\text { on voluntary } \\
\text { gratitude thinking } \\
\text { practice }\end{array}$} & $x$ & $\checkmark$ & $\begin{array}{l}\text { Content of } \\
\text { gratitude thinking }\end{array}$ & Full SRHI & $x$ \\
\hline 袁 & & $\begin{array}{l}\text { Daily online } \\
\text { questionnaire }\end{array}$ & $\begin{array}{l}\text { Voluntary, self-directed } \\
\text { with reference to } \\
\text { instruction sheet }\end{array}$ & & $\begin{array}{l}\text { Text-message reminders } \\
\text { on filling questionnaire if } \\
\text { not done for } 2 \text { or } 3 \text { days }\end{array}$ & $x$ & $x$ & $\begin{array}{l}7 \text {-item } \\
\text { automaticity } \\
\text { subscale }\end{array}$ & $\begin{array}{l}\text { Yes/no for } \\
\text { yesterday to up to } \\
3 \text { days before }\end{array}$ \\
\hline 莺 & & $\begin{array}{l}\text { Post-intervention } \\
\text { Meeting }\end{array}$ & $\begin{array}{l}\text { Compulsory, } \\
\text { led by researcher }\end{array}$ & & \begin{tabular}{|l|} 
Debriefing on habit \\
formation and potential \\
efficacy of gratitude \\
\end{tabular} & $\checkmark$ & $\begin{array}{l}\text { Content of gratitude } \\
\text { thinking \& reasons of } \\
\text { habit formation (or not) }\end{array}$ & \begin{tabular}{|l|} 
Full SRHI; \\
Subjective \\
habit formation
\end{tabular} & $x$ \\
\hline & \multicolumn{9}{|l|}{4 weeks } \\
\hline 芯 & \multirow{3}{*}{8 weeks } & $\begin{array}{l}\text { 4-Week Follow-up } \\
\text { Meeting }\end{array}$ & $\begin{array}{l}\text { Compulsory, } \\
\text { led by researcher }\end{array}$ & $\begin{array}{l}\text { Cash reward upon } \\
\text { attendance of meeting }\end{array}$ & $x$ & $\checkmark$ & $\begin{array}{l}\text { Content of } \\
\text { gratitude thinking }\end{array}$ & Full SRHI & $\begin{array}{l}\text { Repetition in } \\
\text { last } 7 \text { days }\end{array}$ \\
\hline 邹 & & & & & & & & & \\
\hline 흠 & & $\begin{array}{l}\text { 12-Week Follow-up } \\
\text { Meeting }\end{array}$ & $\begin{array}{l}\text { Compulsory, } \\
\text { led by researcher }\end{array}$ & $\begin{array}{l}\text { Cash reward upon } \\
\text { attendance of meeting }\end{array}$ & $x$ & $\checkmark$ & $\begin{array}{l}\text { Content of } \\
\text { gratitude thinking }\end{array}$ & Full SRHI & $\begin{array}{l}\text { Repetition in } \\
\text { last } 7 \text { days }\end{array}$ \\
\hline
\end{tabular}

\# on both gratitude thinking before sleeping and on filling online questionnaire

Fig. 1. Design of the current study with interventions and measures on each occasion specified. 

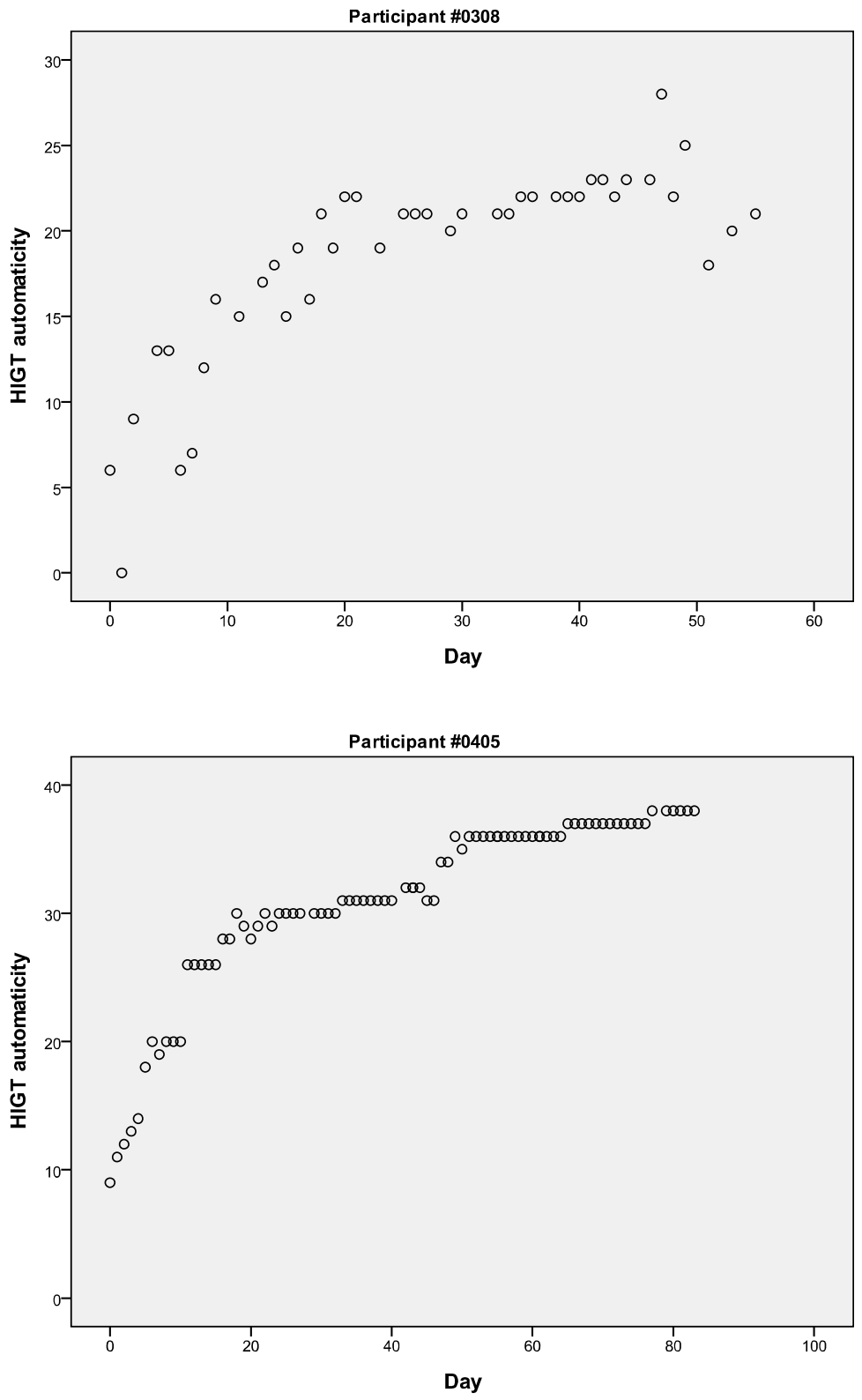

Fig. 2. Two examples of increases in habit automaticity score during the study. One of

the participants did not further enter data after day 54 , while the other continued entering data until the end of the study. 


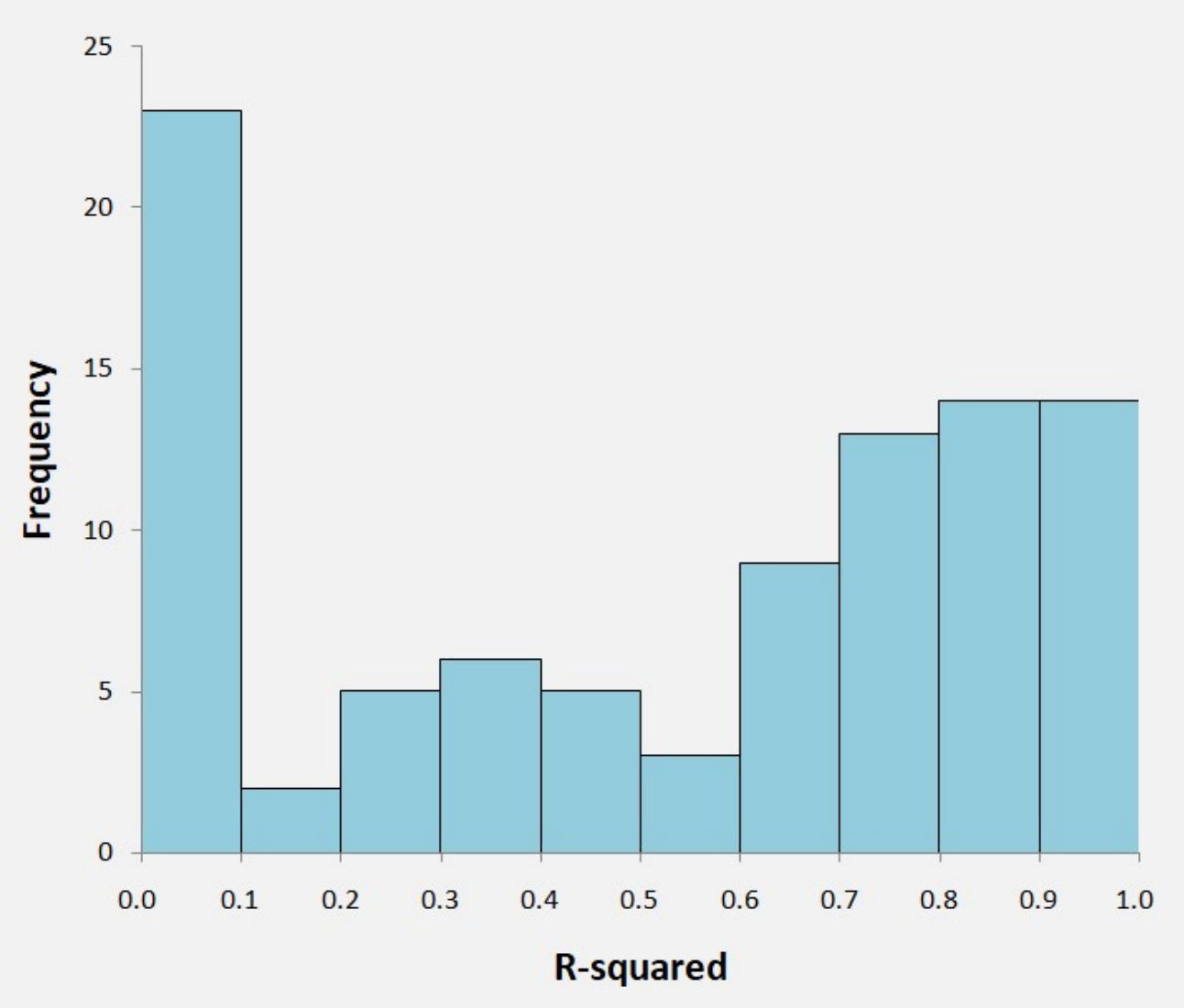

Fig. 3. Histogram showing the distribution of $R^{2}$ values for the 94 participants the nonlinear model was suitable to fit. 

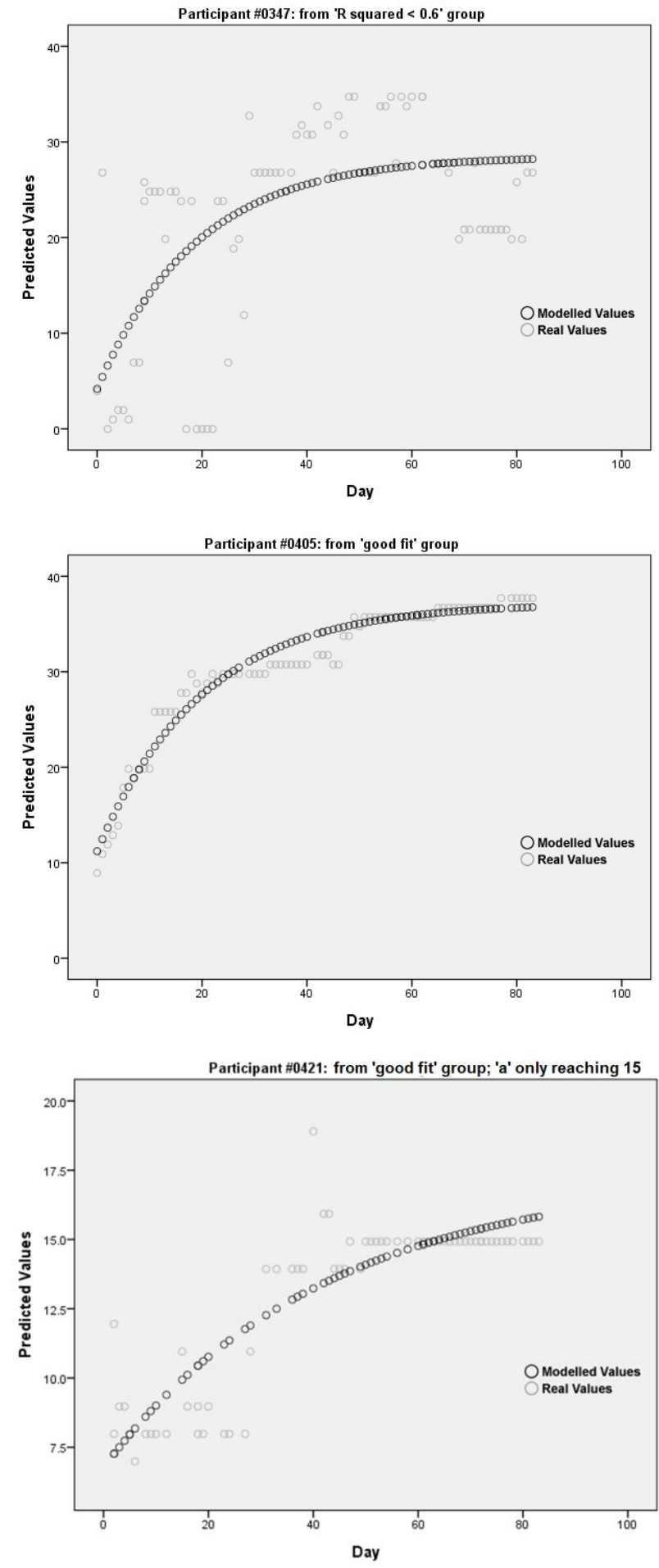

Fig. 4. Three examples of increases in habit automaticity scores during the 84 days showing the scores entered and the curve modelled using nonlinear regression 


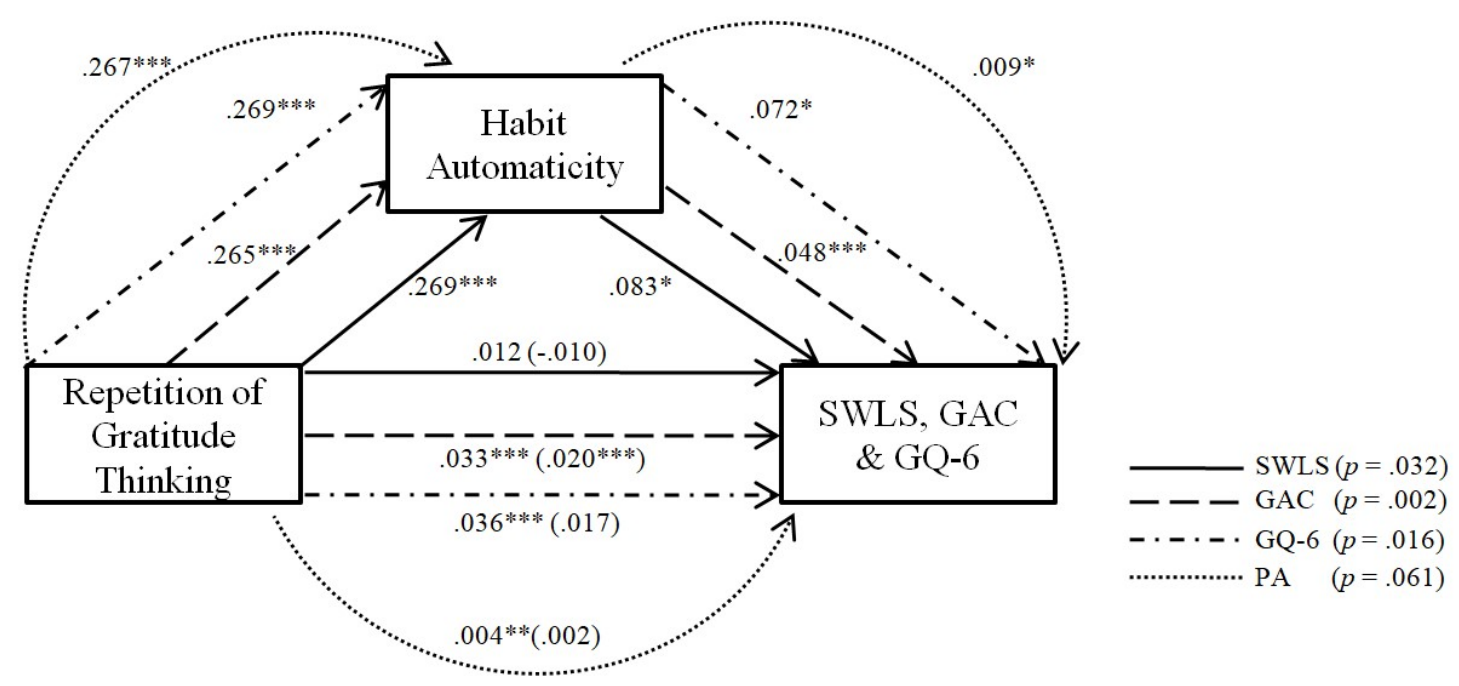

Fig. 5. Regression coefficients for the relationship between repetition of gratitude

thinking and well-being measures (SWLS, GAC \& GQ-6) mediated by habit automaticity 